\title{
The influence on oxy-coal gas compression system operating characteristics from leakage of the quad-section rotary gas-gas preheater
}

\author{
Jianqiang Gao ${ }^{1, a}$, Shaodong Sun ${ }^{2, b}$ \\ ${ }^{1}$ School of Energy Power and Mechanical Engineering, North China Electric Power University, \\ Baoding 071003, China. \\ ${ }^{2}$ School of Energy Power and Mechanical Engineering, North China Electric Power University, \\ Baoding 071003, China. \\ a,b sun1163398838@126.com
}

Keywords: 300MW oxy-coal fired boiler; quad-section rotary gas-gas preheater; leakage; the flue gas compression system; simulation model

\begin{abstract}
The flue gas compression system in a 300MW oxy-coal fired boiler unit is taken as an object of study. By the leakage test of quad-section rotary gas-gas preheater on B-MCR condition, the influence from the leakage on the operation parameters of the flue gas compression system were analyzed. The results present that the leakage of the quad-section rotary gas-gas preheater leads to the temperature drop of the exhaust flue gas, which is beneficial to the elimination of flue gas moisture. But the increase of compressed flue gas flow leads to the increase power of flue gas compressor. In addition, with the increase of air leakage rate of quad-section rotary gas-gas preheater, the rise of flue gas compressor outlet pressure has an influence on the operation performance of deep dehydration equipment, which is unbeneficial to further purification and recovery of the compressed gas.
\end{abstract}

\section{Introduction}

The gas-gas preheater, which is similar to the air preheater, is set up after the economizer in an oxy-coal fired boiler unit. In the gas-gas preheater, the waste heat recovery of exhaust flue gas is used to preheat the oxygen into the furnace and the primary recirculation gas, which is required by the dryness of coal pulverizing system ${ }^{[1]}$. However, the rotary preheaters are widely used by the large thermal power units for its advantages, such as high density of heat transfer, compact structure, corrosion resistance, long service life and low cost ${ }^{[2]}$. Thus, it is better to use the quad-section rotary gas-gas preheater for the preheating of oxygen and the primary recirculation gas. Meanwhile, the primary recirculation gas, which has the highest pressure, is shunted into two parts and the oxygen section is placed between these two primary recirculation gas sections, which can effectively reduce the leakage of oxygen to the exhaust flue gas.

However, there are other leakage problems in the quad-section rotary gas-gas preheater. When the primary recirculation gas, which has the highest pressure, leaks into the exhaust flue gas through the clearance of sealing devices, the physical property parameters of recovered flue gas, such as the density, the specific heat at constant pressure, the adiabatic coefficient are changed and then have an influence on the operation parameters of major equipments in flue gas compression system.

The flue gas compression system is the key system to the capture and recovery of $\mathrm{CO}_{2}$. In the flue gas compression system, the pressure of the flue gas is increased and most moisture of the flue gas is removed by multistage compression and cooling, which is beneficial for the further purification and the recovery of flue gas ${ }^{[3]}$. However, owing to the leakage of the quad-section rotary gas-gas preheater, the physical property parameters changes of the recovered flue gas will make influence on the heat transfer and flow of the flue gas, as well as the operation parameters, such as the efficiency and the pressure ratio of flue gas compressor, the breeding and the outlet flue gas temperature of the flue gas cooler. Now the oxy-coal fired boiler unit is still in the pilot stage, and the change rules of these parameters are needed to be discussed. Therefore, the simulation model 
of quad-section rotary gas-gas preheater was established and coupled with the simulation model of 300MW oxy-coal fired boiler unit ${ }^{[4]}$. By the leakage simulation test of the quad-section rotary gas-gas preheater, the change rules of major operation parameters of flue gas compression system in oxy-coal fired boiler were discussed with different leakage rate, which is beneficial for the commercial popularization and operation optimization of the unit.

\section{Mathematical model}

\section{Definition of the leakage rate of quad-section rotary gas-gas preheater.}

The leakage rate of quad-section rotary gas-gas preheater is defined as the flow ratio of the leakage from the primary recirculation gas into exhaust flue gas section to the primary recirculation gas $^{[5]}$.

$$
\Delta \alpha=\frac{\Delta V}{V_{\mathrm{p}}}
$$

Where $\Delta V$ is the leakage of the primary recirculation gas, $\mathrm{m}^{3} / \mathrm{s} ; V_{\mathrm{p}}$ is the flow of the primary recirculation gas, $\mathrm{m}^{3} / \mathrm{s}$.

The leakage model of quad-section rotary gas-gas preheater.

The leakage from the primary recirculation gas into the exhaust flue gas section:

$$
W_{\mathrm{plk}}=C \sqrt{\left(P_{\mathrm{p}}-P_{\mathrm{g}}\right)}
$$

Where, $C$ is the leakage admittance and its value can be calculated according to the design or the measured of leakage rate; $P g$ and $P_{\mathrm{p}}$ are respectively the pressure of exhaust flue gas and the primary recirculation gas, $\mathrm{kPa}$.

\section{Simulation test and analysis}

The flue gas compression system in a 300MW oxy-coal fired boiler unit is taken as an object of study. By the leakage test of quad-section rotary gas-gas preheater on B-MCR condition, the parameter change rules of flue gas compressor and cooler were analyzed.

The influence on the flue gas cooler operation parameters from the leakage of quad-section rotary gas-gas preheater.

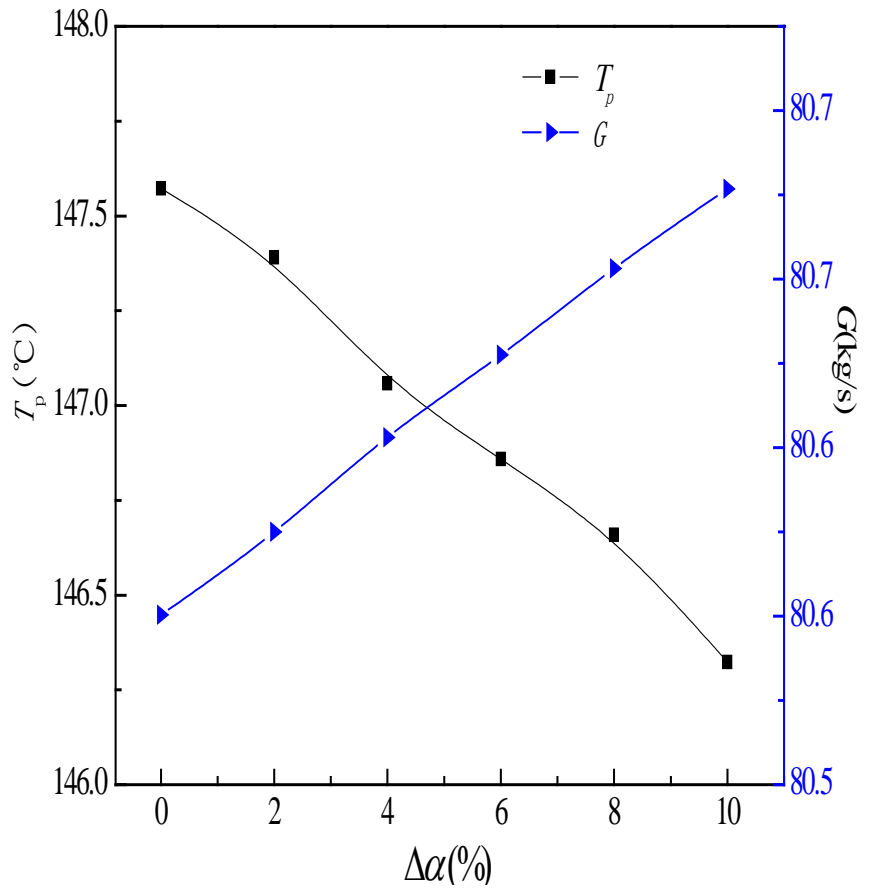

(a) the relationship between leakage rate and exhaust flue gas temperature and the inlet flue gas flow of compression system 


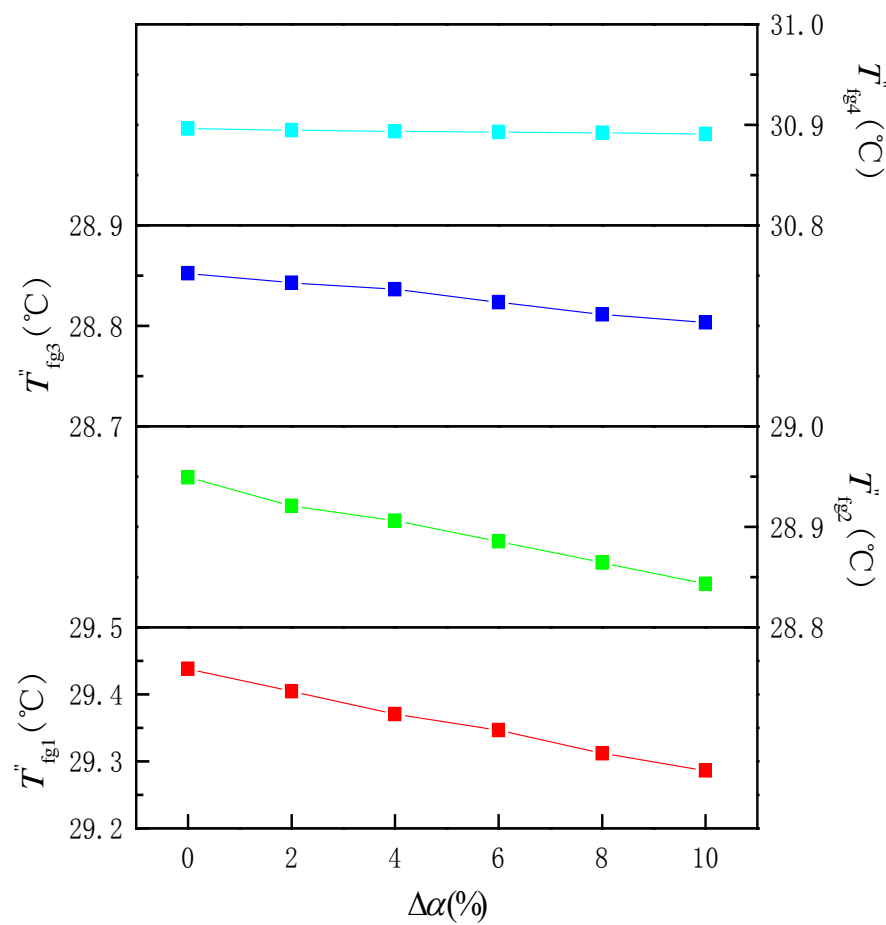

(b) the relationship between leakage rate and exhaust flue gas temperature and the flue gas outlet temperature of all stages gas coolers

Fig. 1 The influence on the flue gas cooler operation parameters from the leakage of quad-section rotary gas-gas preheater

As shown in Fig.1, with the increase of the leakage rate $\Delta \alpha$ of the quad-section rotary gas-gas preheater, the leakage from the primary recirculation gas to the exhaust flue gas section increases. Thus, the exhaust flue gas temperature $T_{\mathrm{p}}$ has a drop trend with the increase of $\Delta \alpha$ for the lower temperature of the leakage. When flue gas leakage is presented in quad-section rotary gas-gas preheater, the inlet flue gas flow $G$ of the compression system increases. Affected by the drop of exhaust flue gas temperature $T_{\mathrm{p}}$, the flue gas outlet temperature of all stages gas coolers have a drop trend. But their decrease amplitude is less than that of the exhaust flue gas because of the increase of the inlet flue gas flow $G$ of the compression system. In addition, the decrease amplitude of the flue gas outlet temperature is serially weak because the heat release of unit flue gas decreases following with the decrease of the exhaust temperature $T_{\mathrm{p}}$.

The influence on the flue gas compressor operation parameters from the leakage of quad-section rotary gas-gas preheater.

As shown in Fig.2, with the increase of the leakage rate $\Delta \alpha$ of the quad-section rotary gas-gas preheater, the inlet flue gas flow $G$ of the compression system increases, which leads to the increase of friction loss $\Delta h_{\mathrm{f}}$ and the decrease of incidence loss $\Delta h_{\mathrm{i}}$. But the total flow loss increases and it leads to the drop of flue gas compressor isentropic efficiency $n_{\mathrm{i}}$. With a constant rotate speed, the power $P$ of flue gas compressor is associated with the compressed flue gas mainly. So $P$ has a rise trend for the influence of inlet flue gas flow $G$. In the flue gas compression system, the increase of the mole proportion $\mathrm{R}_{\mathrm{CO} 2}$ of $\mathrm{CO}_{2}$ in inlet flue gas lead to the decrease of its specific heat at constant pressure, which results in the increase of flue gas compressor pressure ratio $\varepsilon$. The outlet pressure $p_{\text {out }}$ of flue gas compressor rises up following with the increase of flue gas compressor pressure ratio $\varepsilon$. 


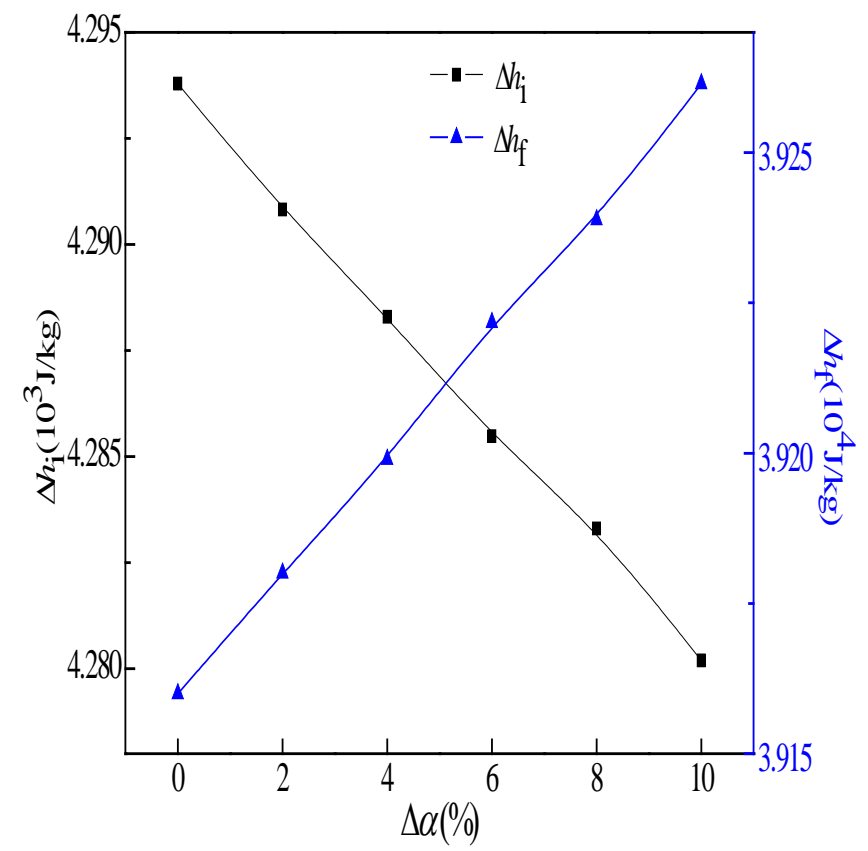

(a) The relationship between leakage rate and single gas compressor incidence loss and the friction loss

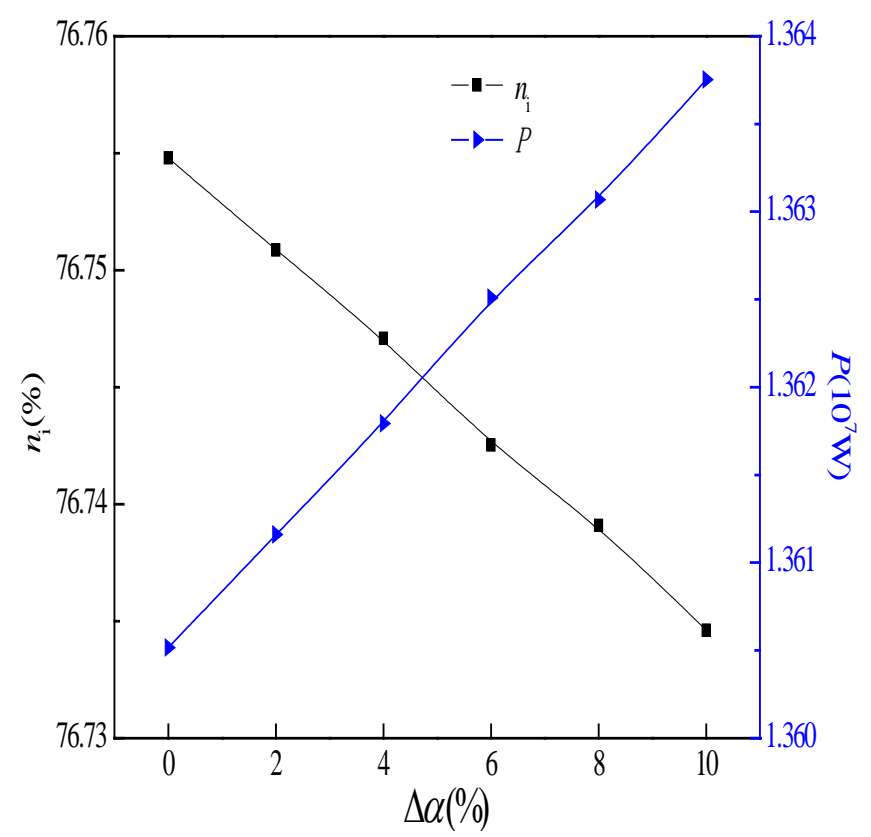

(b) The relationship between leakage rate and single gas compressor isentropic efficiency and power 


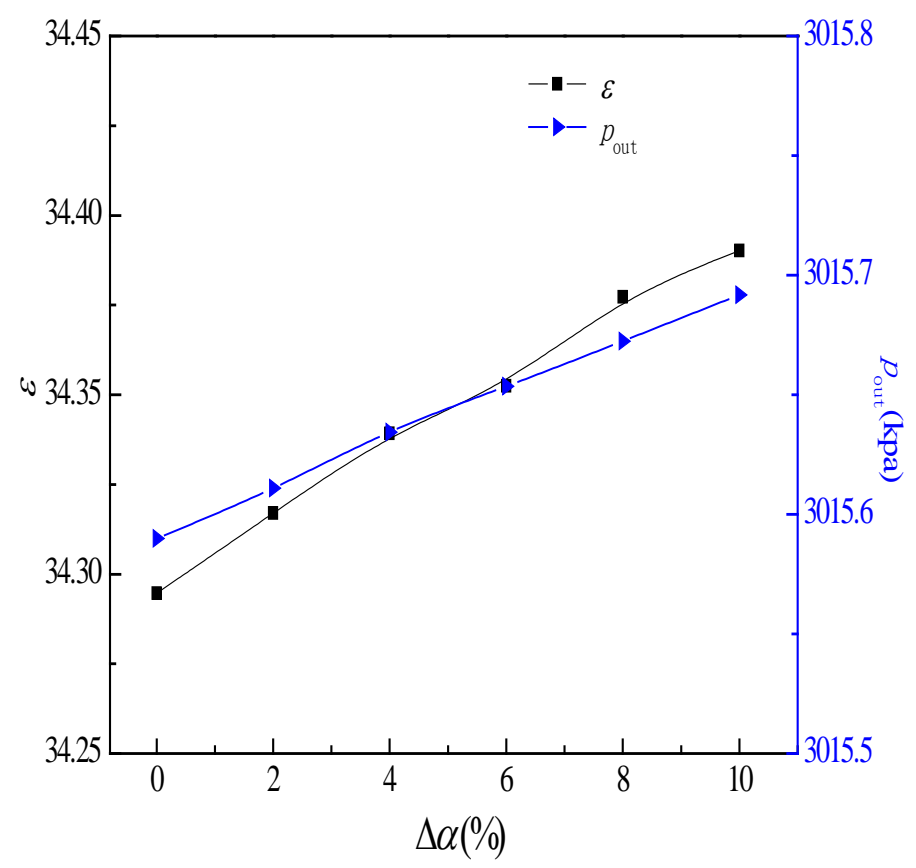

(c) The relationship between leakage rate and gas compressor pressure ratio and outlet pressure

Fig.2 The influence on the flue gas compressor operation parameters from the leakage of quad-section rotary gas-gas preheater

\section{Summary}

The leakage of the quad-section rotary gas-gas preheater leads to the temperature drop of the exhaust flue gas, which is beneficial to the elimination of moisture in the flue gas. But the increase of compressed flue gas flow leads to the increase power of flue gas compressor. In addition, with the increase of air leakage rate of quad-section rotary gas-gas preheater, the rise of flue gas compressor outlet pressure has an influence on the operation performance of deep dehydration equipment, which is unbeneficial to further purification and recovery of the compressed gas.

\section{References}

[1] Weiping Yan, Cuili Mi. Study on conceptual design of utility boiler burning oxygen-enriched pulverized coal[J]. Thermal Power Generation, 2011,40(02):1-7.

[2] Hongyue Wang, Xiaolong Bi, Fengqi Si.Comprehensive air leakage distribution models for rotary air preheaters of 300MW units[J]. East China Electric Power, 2006, 34(1): 44-48.

[3] Hongbin Kong, Chaohui Liu, Sheng Chen, et al.Process Simulation and Optimization of a 600 MW O2/CO2 Power Plant[J].Proceedings of the CSEE,2012,32(2):53-60.

[4] Zhifu Hou. Study of Real-time Simulation Model for Oxy-coal Fired Boiler Unit[D]. North China Electric Power University, 2012.

[5] Jianqiang Gao, Likun Wang, Shaodong Sun, Research on Affecting of Air Leakage on Parameters of a 300 MW Oxy-coal Fired Boiler [J] North China Electric Power University (Natural Science), 2015, 2: 012. 